\title{
PENGARUH MARKETING MIX 4P DAN PERCEIVED QUALITY TERHADAP PURCHASE DECISION SMARTPHONE VIVO
}

\author{
Liandri Darma Putra \\ Program Studi Magister Manajemen Universitas Tarumanagara \\ liandridputra@gmail.com \\ Eko Harry Susanto \\ Program Studi Magister Manajemen Universitas Tarumanagara
}

\begin{abstract}
The purpose of this study is to analyze the effect of the marketing mix (product, price, promotion and place) and perceived quality on purchasing decisions. The research implemented quantitative method, in which questionnaire were distributed to a total of 120 respondents, thus enabling the data to be analyzed. Data were collected from respondents in Jakarta Barat regions. Data were analyzed by SPSS version 20.00 for windows using multiple linier regression method. After conducting data analysis, it was revealed that place and perceived quality have a significant impact on purchase decision. Meanwhile product, price and promotion doesn't have a positive impact toward purchase decision. But all variables simultaneously have a significant effect toward purchase decision.
\end{abstract}

Abstrak : Tujuan dari penelitian ini adalah untuk menganalisis pengaruh bauran pemasaran (produk, harga, promosi dan tempat) dan persepsi kualitas terhadap keputusan pembelian. Penelitian ini menerapkan metode kuantitatif, di mana kuesioner dibagikan kepada total 120 responden, sehingga memungkinkan data yang akan dianalisis. Data dikumpulkan dari responden di wilayah Jakarta Barat. Data dianalisis dengan SPSS versi 20.00 for windows menggunakan metode regresi linier berganda. Setelah melakukan analisis data, terungkap bahwa tempat dan kualitas yang dirasakan memiliki dampak signifikan terhadap keputusan pembelian. Sementara itu produk, harga, dan promosi tidak memiliki dampak positif terhadap keputusan pembelian. Tetapi semua variabel secara bersamaan memiliki pengaruh yang signifikan terhadap keputusan pembelian.

Keywords : Product, Price, Promotion, Place, Marketing Mix, Perceived Quality, Purchase decision

\section{PENDAHULUAN}

Pada era dimana teknologi terus berkembang, sekarang ini ponsel bukan hanya sekedar memiliki fungsi komunikasi saja tetapi juga dapat digunakan untuk mengakses internet. Kebutuhan masyarakat akan alat telekomunikasi ini pun semakin meningkat seiring dengan perubahan pada tingkat pendapatan, gaya hidup, dan pergerseran fungsi dari ponsel itu sendiri. Media yang menggunakan internet ini biasanya disebut sebagai media siber yang dimana merupakan media yang memanfaatkan internet untuk melakukan pengelolaan, pengorganisasian, dan penyebaran informasi (Susanto, 2018). Banyaknya perusahaan gadget yang ada di Indonesia ini menyebabkan adanya persaingan bisnis untuk menarik pelanggan sebanyak-banyaknya. Hal tersebut menyebabkan semakin banyak merek dan tipe smartphone yang beredar di pasaran Indonesia dan semakin banyak pula pilihan bagi konsumen dalam membeli suatu smartphone. Merek-merek smartphone yang beredar di pasaran sekarang ini sangatlah beragam, menurut firma riset pasar IDC, 5 merek smartphone yang mendominasi di Indonesia pada tahun 2016-2017 adalah Samsung, Oppo, Advan, Asus, dan Vivo. data yang diperole lembaga riset IDC untuk Quarterly Mobile Phone Tracker kuartal-IV 2017 menunjukkan pencapaian positif Vivo yang menutup 2017 sebagai 3 besar smartphone brand 
di Indonesia dengan presentase market share sebesar 11 persen. Melanjutkan pencapaian pada tahun ini, seri terbaru Vivo V9 juga mencatat rekor pemesanan pada online pre-order, serta puluhan ribu penjualan pada momen Super Selling Dayyang dibuka pada 5 April 2018. Dalam proses pembelian suatu smartphone banyak hal yang menjadi pertimbangan dikarenakan banyaknya merek smartphone yang beredar di pasar dengan berbagai tingkatan kualitas dan tingkatan harga serta adanya persepsi akan kualitas dari konsumen terhadap sebuah smartphone. Konsumen sendiri dalam hal pengambilan keputusan pembelian smartphone khususnya vivo memiliki pertimbangan-pertimbangan ketika memutuskan untuk melakukan pembelian. Konsumen membeli smartphone didorong oleh adanya kebutuhan akan komunikasi dan variabel-variabel marketing mix dan persepsi konsumen akan kualitas dari produk tersebut merupakan pertimbangan yang mempengaruhi konsumen dalam melakukan pembelian. Tujuan dari penelitian ini adalah untuk mengetahui pengaruh atau dampak dari product, price, promo, place dan perceived quality terhadap purchase decision smartphone Vivo di Jakarta Barat.

\section{TINJAUAN PUSTAKA}

\section{Marketing Mix}

Marketing mix (bauran pemasaran) adalah alat bisnis yang digunakan dalam suatu pemasaran dan sering dikaitkan dengan 4P, yaitu Harga, Produk, Tempat, dan Promosi. Faktorfaktor tersebut merupakan faktor penting untuk menentukan penawaran suatu produk atau merk di pasar (Sunardi, Ibrahim \& Tain, 2016). Adapun definisi lain dari marketing mix ialah merupakan unsur-unsur pemasaran yang saling terkait, dibaurkan, diorganisir, dan digunakan dengan tepat sehingga perusahaan dapat mencapai tujuan pemasaran dengan efektif dan dapat memuaskan kebutuhan dan keinginan dari konsumen. (Zeithaml \& Bitner, 1996).

Berikut definisi dan konsep tentang variabel-variabel dalam marketing mix yaitu:

\section{- Product}

Product adalah segala sesuatu yang dapat ditawarkan kepada pasar untuk memuaskan suatu keinginan atau kebutuhan, termasuk barang fisik, jasa, pengalaman, acara, orang, tempat, property, organisasi, informasi, dan ide (Kotler \& Keller, 2015).

- Price

Price adalah sejumlah uang yang ditagihkan atas suatu produk dan jasa atau jumlah dari nilai yang ditukarkan para pelanggan untuk memperoleh manfaat dari memiliki ataupun manfaat dari memiliki suatu produk atau jasa (Kotler et al., 2017).

\section{- Promotion}

Promotion adalah aktivitas yang mengkomunikasikan keunggulan produk dan membujuk pelanggan sasaran untuk membelinya (Kotler \& Keller, 2015). Salah satu dari jenis komunikasi yang sering digunakan dalam promosi ialah komunikasi massa yang merupakan komunikasi melalui media massa yang ditujukan kepada sejumlah khalayak yang besar. (Susanto, 2018).

- Place

Place (Saluran Distribusi) adalah sekelompok organisasi yang saling bergantung dan terlibat dalam proses pembuatan produk atau jasa yang disediakan untuk digunakan atau di konsumsi. Saluran distribusi dapat juga di artikan sebagai seperangkat alur yang diikuti produk atau jasa setelah produksi, berakhir dalam pembelian dan digunakan oleh pengguna akhir (Kotler \& Keller, 2015)

\section{Perceived Quality}

Perceived quality dapat didefinisikan sebagai penilaian konsumen tentang keunggulan suatu produk secara keseluruhan (Zeithaml, 1988). Perceive quality juga dapat diartikan sebagai sebuah variabel penilaian yang cenderung menjadi suatu model yang menjelaskan niat perilaku konsumen (Sanyal \& Datta, 2011). Perceived quality mencerminkan perasaan pelanggan secara menyeluruh mengenai suatu merek. 


\section{Purchase Decision}

Keputusan pembelian sendiri menurut Kotler \& Keller (2015) merupakan hasil dari proses yang terdiri dari lima tahapan dimana tahapan-tahapan tersebut antara lain ialah: (1) pengenalan masalah (2) pencarian informasi (3) pengevaluasian alternatif (4) keputusan pembelian (5) perilaku setelah pembelian.

Berdasarkan uraian variabel tersebut maka dapat disimpulkan hipotesis pada penelitian ini adalah sebagai berikut:

H1 : Terdapat pengaruh antara variabel Product terhadap Purchase Decision Smartphone Vivo di Jakarta Barat.

H2 : Terdapat pengaruh antara variabel Price terhadap Purchase Decision Smartphone Vivo di Jakarta Barat.

H3 : Terdapat pengaruh antara variabel Promotion terhadap Purchase Decision Smartphone Vivo di Jakarta Barat.

H4 : Terdapat pengaruh antara variabel Place terhadap Purchase Decision Smartphone Vivo di Jakarta Barat.

H5 : Terdapat pengaruh antara variabel Perceived quality terhadap Purchase Decision Smartphone Vivo di Jakarta Barat.

\section{Kerangka pemikiran.}

Penelitian ini dilakukan berdasarkan variabel bauran pemasaran (produk, harga, promosi, dan saluran distribusi) dan perceived quality terhadap keputusan pembelian smartphone Vivo. Berikut bagan dari kerangka pemikiran penelitian ini:

Gambar 1.1

Kerangka Pemikiran

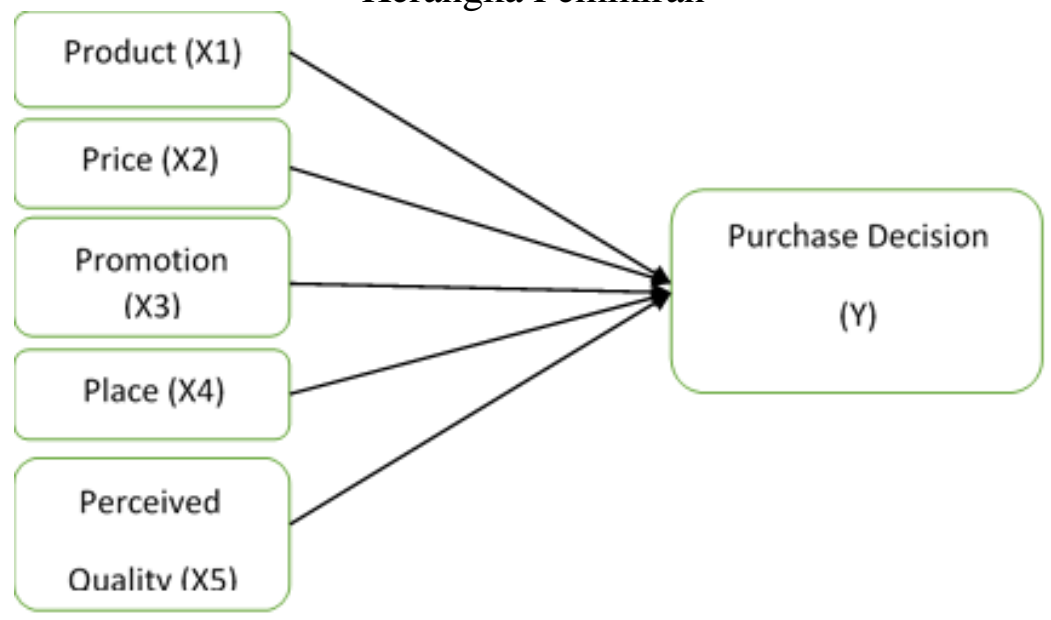

\section{Metode Penelitian}

Jenis penelitian yang dilakukan adalah penelitian primer. Penelitian merupakan penelitian survey yang merupakan studi yang bersifat kuantitatif yang digunakan untuk meneliti gejala suatu kelompok atau perilaku (Sarwono, 2006) dan tidak melakukan perubahan terhadap variabel-variabel yang diteliti (Siregar, 2013). Data dikumpulkan dengan metode cross section dimana data yang dikumpulkan pada suatu waktu tertentu untuk menggambarkan keadaan pada waktu tersebut. Pengumpulan data dilakukan dengan menyebarkan kuesioner dan diperoleh sampel sebanyak 120 responden. pengukuran dilakukan dengan menggunakan skala likert Menurut Sugiyono (2017) skala likert digunakan untuk mengukur sikap, pendapat, dan persepsi seseorang atau sekelompok orang tentang fenomena sosial.

\section{Operasionalisasi Variabel}

Operasionalisasi variabel berisi petunjuk pengukuran suatu variabel. Dalam penelitian ini opersionalisasi variabel dapat kita lihat pada tabel berikut 
Tabel 1.1

Operasionalisasi Variabel

\begin{tabular}{|c|c|c|c|c|}
\hline No & Variabel & Definisi Variabel & Indikator & Pengukuran \\
\hline 1 & Product & $\begin{array}{l}\text { Segala sesuatu yang dapat } \\
\text { ditawarkan kepada pasar } \\
\text { untuk memuaskan suatu } \\
\text { keinginan atau kebutuhan } \\
\text { termasuk barang fisik, jasa, } \\
\text { pengalaman, acara, orang, } \\
\text { tempat, properti, organisasi, } \\
\text { informasi, dan ide (Kotler \& } \\
\text { Keller, 2015). }\end{array}$ & $\begin{array}{l}\text { 1. Design } \\
\text { 2. Technology } \\
\text { 3. Quality } \\
\text { 4. Packing } \\
\text { 5. Guarantees } \\
\text { (Isoraite, 2016) }\end{array}$ & $\begin{array}{c}\text { Skala } \\
\text { Likert } \\
(1-5)\end{array}$ \\
\hline 2 & Price & $\begin{array}{l}\text { Nilai yang dibayarkan oleh } \\
\text { konsumen } \quad \text { (Owomoyela, } \\
\text { Olasunkanmi } \quad \text { \&Oyeniyi, } \\
\text { 2013). }\end{array}$ & $\begin{array}{l}\text { 1. Suitability Price } \\
\text { 2. Discount } \\
\text { (Brata, Husani \& Ali, } \\
\text { 2017) }\end{array}$ & $\begin{array}{c}\text { Skala } \\
\text { Likert } \\
(1-5)\end{array}$ \\
\hline 3 & Promotion & $\begin{array}{l}\text { Aktivitas yang } \\
\text { mengkomunikasikan } \\
\text { keunggulan produk dan } \\
\text { membujuk pelanggan } \\
\text { sasaran untuk membelinya } \\
\text { (Kotler \& Keller, 2015). }\end{array}$ & $\begin{array}{l}\text { 1. Advertising } \\
\text { 2. Public Relations } \\
\text { 3. Personal Selling } \\
\text { 4. Direct Marketing } \\
\text { (Kotler et al., 2017). }\end{array}$ & $\begin{array}{l}\text { Skala } \\
\text { Likert } \\
(1-5)\end{array}$ \\
\hline 4 & Place & $\begin{array}{l}\text { Seperangkat alur yang } \\
\text { diikuti produk atau jasa } \\
\text { setelah produksi, berakhir } \\
\text { dalam pembelian dan } \\
\text { digunakan oleh pengguna } \\
\text { akhir (Kotler \& Keller, } \\
\text { 2015). }\end{array}$ & $\begin{array}{l}\text { 1. Channel } \\
\text { 2. Logistics } \\
\text { 3. Product Inventory } \\
\text { 4. Transport } \\
\text { 5. Place/ Location } \\
\text { (Isoraite, 2016) }\end{array}$ & $\begin{array}{c}\text { Skala } \\
\text { Likert } \\
(1-5)\end{array}$ \\
\hline 5 & $\begin{array}{l}\text { Perceived } \\
\text { Quality }\end{array}$ & $\begin{array}{l}\text { Penilaian konsumen tentang } \\
\text { keungulan suatu produk } \\
\text { secara keseluruhan } \\
\text { (Zeithaml, 1988). }\end{array}$ & $\begin{array}{l}\text { 1. Karyawan memakai } \\
\text { seragam, serta } \\
\text { berpenampilan rapi. } \\
\text { 2. Karyawan mampu } \\
\text { memberikan } \\
\text { pelayanan secara } \\
\text { tepat waktu } \\
\text { 3. Produk yang } \\
\text { ditawarkan menarik. } \\
\text { (Liao, Widowati, \& Hu, } \\
\text { 2006). }\end{array}$ & $\begin{array}{c}\text { Skala } \\
\text { Likert } \\
(1-5)\end{array}$ \\
\hline 6 & $\begin{array}{l}\text { Purchase } \\
\text { Decision }\end{array}$ & $\begin{array}{l}\text { Proses yang dilewati oleh } \\
\text { seorang konsumen ketika } \\
\text { konsumen tersebut } \\
\text { memiliki suatu produk. }\end{array}$ & $\begin{array}{l}\text { 1. Pengenalan masalah } \\
\text { 2. Pencarian informasi } \\
\text { 3. Pengevaluasian } \\
\text { alternatif } \\
\text { 4. Keputusan } \\
\text { pembelian } \\
\text { 5. Perilaku setelah } \\
\text { pembelian } \\
\text { (Kotler \& Keller, 2015) }\end{array}$ & $\begin{array}{c}\text { Skala } \\
\text { Likert } \\
(1-5)\end{array}$ \\
\hline
\end{tabular}




\section{Hasil Analisis Data}

Dalam Penelitian ini dilakukan tiga jenis pengujian yaitu Uji-t, Uji F dan koefisien determinasi ganda dengan menggunakan program SPSS version 20.00 for windows. Persamaan regresi yang dalam penelitian ini Purchase Decision $(\mathrm{Y})=15,592-0.034$ (Product / X1) + 0,192 (price / X2) + 0,189 (Promotion / X3) + 0,288 (Place / X4) - 0,555 (Perceived Quality / X5).

Dari hasil uji t diperoleh hasil bahwa terdapat pengaruh antara variabel place dan perceived quality terhadap purchase decision dan tidak ada pengaruh antara variabel product, price dan promotion terhadap purchase decision. Dan pada uji f yang dilakukan didapatkan hasil bahwa seluruh variabel product, price, promotion, place dan perceived quality secara simultan berpengaruh terhadap purchase decision. Variabel-variabel independent dalam penelitian ini memiliki nilai koefisien determinasi sebesar 7,7\% dimana hanya 7,7\% variabel purchase decision dapat dijelaskan oleh variabel-variabel independent tersebut.

\section{Kesimpulan dan Saran}

Berdasarkan hasil pembahasan dan hasil penelitian pada bab sebelumnya, maka kesimpulan dari penelitian adalah sebagai berikut:

1. Dari hasil uji t yang dilakukan nilai signifikani yang diperoleh sebesar 0,801 >0,05 maka tidak terdapat pengaruh antara product terhadap purchase decision.

2. Dari hasil uji t yang dilakukan nilai signifikani yang diperoleh sebesar 0,421 >0,05 maka tidak terdapat pengaruh antara price terhadap purchase decision.

3. Dari hasil uji t yang dilakukan nilai signifikani yang diperoleh sebesar 0,223>0,05 maka tidak terdapat pengaruh antara promotion terhadap purchase decision.

4. Dari hasil uji t yang dilakukan nilai signifikani yang diperoleh sebesar 0,033 < 0,05 maka terdapat pengaruh antara place terhadap purchase decision.

5. Dari hasil uji t yang dilakukan nilai signifikani yang diperoleh sebesar 0,009 < 0,05 maka terdapat pengaruh antara perceived quality terhadap purchase decision.

Dari hasil penelitian ini maka peneliti memberi beberapa saran bagi perusahaan maupun akademisi dan peneliti selanjutnya.

1. Bagi perusahaan

Peneliti menyarankan agar Vivo menaruh fokus untuk meningkatkan brand image dari Vivo sehingga dapat meningkatkan brand awareness konsumen akan Vivo maupun produk-produk yang ditawarkan.

2. Bagi akademisi dan peneliti selanjutnya

Untuk pengembangan ke depan dari penelitian ini, peneliti menyarankan penambahan variabel-variabel lainnya yang belum tercakup dalam penelitian ini serta penambahan jumlah sampel dan cakupan wilayah penelitian.

\section{Daftar Pustaka}

Brata B H., Husani S., \& Ali H. (2017). The Influence of Quality Products, Price, Promotion, and Location to Product Purchase Decision on Nitchi At PT. Jaya Swarasa Agung in Central Jakarta, Vol 2, 443-445.

Isoraite, M. (2016) Marketing Mix Theoretical Aspects, International Journal of Research Granthaalayah, Vol.4 Issue:6, 25-37.

Kotler, P. and Keller, K.L. (2015). Marketing Management. fifteenth Edition. Pearson Prentice. Kotler P., Armstrong G., Ang S., Tan C., Yau O., Leong S. (2017). Principles of Marketing An Asian Perspective. Fourth Edition. Pearson Education Limited.

Liao, S. H., Widowati, R. P. A., \& Hu, D. C., (2006). Study Of The Relationship Between Brand Awareness, Brand Association, Perceived Quality, And Brand Loyalty, Seoul: BAI 2008 Intl.Conference on Business and Information. 
Sanyal, S., N. \& Datta, S., J. (2011) "The effect of perceived quality on brand equity: an empirical study on generic drugs", Asia Pacific Journal of Marketing and Logistics, Vol. 23 Issue: 5, pp.604-625.

Sarwono, J. (2006). Metode Penelitian Kuantitatif \& Kualitatif. Yogyakarta: Graha Ilmu.

Siregar., S. (2013) Metode Penelitian Kuantitatif, Jakarta: Kencana Prenada Media Group.

Sugiyono. (2017). Metode Penelitian Kuantitatif, Kualitatif, dan R\&D. Bandung : Alfabeta, $\mathrm{CV}$.

Sunardi, Ibrahim, Tain. (2016). Analysis The Effect of Marketing Mix In Purch Decision of Growing Up Milk on Three Socio-Economic Classes in Malang. Agricultural SocioEconomics Journal. Vol. XVI, 87-96.

Susanto E. H. (2018). Komunikasi Manusia: Teori dan Praktek Dalam Penyampaian Gagasan.Jakarta: Mitra Wacana Media.

Zeithaml, Vlarie A. (1988). Consumer Perceptions of Price, Quality and Value : A Means-End Model and Synthesis of Evidence", Journal of Marketing, Vol.52, 2-22.

Zeithaml, Vlarie A \& Bitner, Mary J. (1996). Service Marketing: Integrating Customer Focus Across The Firm. USA: The McGraw Hill Companies. 